2004

\title{
The Impact of HIV-Associated Neuropsychological Impairment on Everyday Functioning
}

Robert K. Heaton

University of California - San Diego

Thomas D. Marcotte

University of California - San Diego

Monica Rivera-Mindt

Fordham University

Joseph Sadek

University of California - San Diego

David J. Moore

San Diego State University/University of California - San Diego

See next page for additional authors

Follow this and additional works at: https://fordham.bepress.com/psych_facultypubs

Part of the Psychology Commons

\section{Recommended Citation}

Heaton, Robert K.; Marcotte, Thomas D.; Rivera-Mindt, Monica; Sadek, Joseph; Moore, David J.; Bentley, Heather; McCutchan, J Allen; Reicks, Carla; Grant, Igor; and The HNRC Group, "The Impact of HIV-Associated Neuropsychological Impairment on Everyday Functioning" (2004). Psychology Faculty Publications. 15.

https://fordham.bepress.com/psych_facultypubs/15 
Authors

Robert K. Heaton, Thomas D. Marcotte, Monica Rivera-Mindt, Joseph Sadek, David J. Moore, Heather Bentley, J Allen McCutchan, Carla Reicks, Igor Grant, and The HNRC Group 


\title{
The impact of HIV-associated neuropsychological impairment on everyday functioning
}

\author{
ROBERT K. HEATON, ${ }^{1,2}$ THOMAS D. MARCOTTE, ${ }^{1}$ MONICA RIVERA MINDT, ${ }^{4}$ \\ JOSEPH SADEK, ${ }^{1}$ DAVID J. MOORE, ${ }^{3}$ HEATHER BENTLEY,${ }^{1}$ J. ALLEN MCCUTCHAN,${ }^{1}$ \\ CARLA REICKS, ${ }^{1}$ IGOR GRANT, ${ }^{1,2}$ AND THE HNRC GROUP \\ ${ }^{1}$ Department of Psychiatry, University of California at San Diego, San Diego, California \\ ${ }^{2}$ VA San Diego Health Care System, San Diego, California \\ ${ }^{3}$ San Diego State University/University of California, San Diego Joint Doctoral Program in Clinical Psychology, \\ San Diego, California \\ ${ }^{4}$ Department of Psychology, Fordham University, New York, New York \\ (Received December 16, 2002; Revised August 15, 2003; Accepted August 21, 2003)
}

\begin{abstract}
HIV-1 infection can be associated with neuropsychological (NP) deficits ranging from subtle to severe. The purpose of this study was to evaluate the functional, or "real-world" impact of HIV-associated NP impairment in a group of 267 HIV-infected participants. All participants received comprehensive NP, neuromedical, and standardized functional evaluations that included laboratory measures of shopping, cooking, financial management, medication management and vocational abilities. Compared to NP-normal participants, those with NP impairment performed significantly worse on all laboratory measures of everyday functioning. Multivariate analyses revealed that the NP ability domains of Abstraction/Executive Function, Learning, Attention/Working Memory and Verbal abilities most strongly and consistently predicted failures on the functional battery. Both NP impairment and impairment on the functional battery were significantly associated with subjective experiences of cognitive difficulties, as well as unemployment and increased dependence in activities of daily living; multivariate prediction models that also considered depressed mood and biological measures of disease progression revealed that impairment on the functional battery and depression were the only unique predictors of all three indicators of "real-world" functioning. The current results add to growing evidence concerning the clinical significance of HIV-associated NP impairment. Objective, laboratory based functional measures, such as those used here, may compliment NP testing in future studies directed at understanding the impact on life quality of central nervous system disorders and their treatments. Finally, there is a need for additional research investigating the apparently independent effect of depression on level of everyday functioning in HIV infected persons. (JINS, 2004, 10, 317-331.)
\end{abstract}

Keywords: HIV, Activities of daily living, Everyday functioning, Cognition

\section{INTRODUCTION}

HIV-infection can be associated with CNS involvement and changes in neurobehavioral status, particularly in advanced stages of the illness (Bornstein et al., 1992; Grant et al., 1987; Heaton et al., 1995; Stern et al., 1991). Neuroimaging and neuropsychological (NP) studies suggest initial preferential involvement of frontostriatal circuitries, reduction

NOTE: Dr. Erin D. Bigler served as action editor during the course of this review.

Reprint requests to: Robert K. Heaton, University of California, Department of Psychiatry (0603-G), 9500 Gilman Drive, La Jolla, CA 92093-0603. in white matter volumes, and a spotty pattern of mild NP impairments, with increasing structural abnormalities and NP impairment as HIV disease state advances (Heaton et al., 1995; Jernigan et al., 1993; Stout et al., 1998).

A common difficulty in establishing HIV-related neurocognitive diagnoses, either for research or clinical purposes, is obtaining reliable and valid data concerning the patients' levels of competence in everyday functioning. Changes in everyday functioning are required for the diagnosis of HIV-related syndromic neurobehavioral disorders such as minor cognitive motor disorders (MCMD) and HIV associated dementia (HAD; American Academy of Neurology AIDS Task Force, 1991). However, most available instruments for detecting these changes, such as self-report 
questionnaires and checklists (Lawton et al., 1969), or even more direct and objective measures of functional ability such as the Direct Assessment of Functional Status (DAFS; Lowenstein et al., 1995), are designed for elderly subjects with dementing disorders (e.g., dementia of the Alzheimer's type). Although useful in these populations, such instruments have proven insensitive to the mild NP impairments observed in the generally younger HIV-infected $(\mathrm{HIV}+)$ adult population.

At present, the few available studies concerning functional impact of HIV-related NP deficits suggest that these deficits are associated with impaired driving ability, worse performance on standardized work samples, increased unemployment and complaints of problems in vocational functioning and everyday living (Albert et al., 1995; Benedict et al., 2000; Heaton et al., 1996; Mapou et al., 1993; Marcotte et al., 1999; Stern et al., 1991). Of particular importance to HIV + patients is the ability to effectively manage their antiretroviral medications. Preliminary studies suggest that HIV+ participants with impairments in memory, executive function, and psychomotor functioning can demonstrate significant difficulties with performance on structured tasks of medication management ability, as well as adherence to medication regimens in everyday life (Albert et al., 1999; Hinkin et al., 2002).

The above studies consistently suggest that HIV-associated cognitive impairment can interfere with everyday functioning. Nevertheless, traditional NP tests used to identify such impairments have, at best, limited face validity as measures of everyday life requirements. It may well be that standardized versions of essential everyday tasks would also be sensitive to disease related changes in cognitive abilities, yet more readily interpretable with respect to questions about patients' everyday functioning. The field remains hampered by the lack of a sensitive, comprehensive functional battery for use with HIV patients (and those with other disorders that present with a pattern of relatively mild NP impairments), in order to make empirically validated predictions of functional ability. As was pointed out in one recent study which used questionnaires and gross measures of functional ability, more refined measures are needed in order to better evaluate the clinical or real-world significance of HIV treatment effects (Schiffito et al., 2001).

The purpose of this study was to extend prior investigations of the clinical significance of NP impairment in a large cohort of HIV-infected individuals, by first evaluating the psychometric properties of newly developed functional measures, and then assessing the concurrent validity of a relatively comprehensive functional battery by examining the cross-sectional relationships both with NP impairments and important aspects of everyday functioning. Areas of focus included instrumental activities of daily living (IADLs), required for living independently, as well as vocational ability. The former activities are especially relevant for persons in more advanced disease states and/or more severe NP impairment; vocational abilities are more relevant to HIV + persons with minimal to mild NP impair- ment who are well enough to work. It was hypothesized that (1) compared to NP-normal HIV + participants, NPimpaired subjects would perform worse on laboratory measures of everyday functioning; and (2) impairments on NP and laboratory measures would predict increased problems in everyday functioning outside of the laboratory (i.e., perceived cognitive difficulties, need for more assistance in managing daily living tasks, more "downward drift" in the kinds of jobs they were performing, and higher unemployment rates). Although most everyday functioning tasks involve numerous cognitive abilities, and therefore may be disrupted by a variety of cognitive impairments, exploratory multivariate analyses will be used to determine which NP ability deficits most strongly predict failures in the functional test battery. Finally, receiver operating characteristic (ROC) curve analyses and likelihood ratios will be used to demonstrate the probabilities of increased dependence in everyday living, based upon performance on the laboratorybased functional battery.

\section{METHODS}

\section{Research Participants}

Table 1 provides a summary of demographic, immune status and diagnostic information for the total sample of 267 HIV-infected adults who participated in this study. Participants were recruited by the HIV Neurobehavioral Research Center (HNRC), an NIMH-funded center for the study of the prevalence, features, course and pathogenesis of HIV involvement in the central nervous system (CNS). As part of their participation in the HNRC, participants completed comprehensive neuromedical and NP assessments. In addition, all participants underwent a urine toxicology screen on the NP visit day, and all participants were negative for illicit substance use (i.e., non-prescribed stimulants, opiates, benzodiazepines, barbiturates, sedatives, etc.). Poten-

Table 1. Demographic and disease characteristics of 267 HIV-infected participants

\begin{tabular}{lcc}
\hline \hline Demographic variable & $M$ or $P$ & $S D$ \\
\hline Age & 39.32 & 7.52 \\
Education & 13.29 & 2.4 \\
CD4 Cell Count & 356.5 & 267 \\
Percent Male & $84 \%$ & - \\
Ethnicity & & \\
$\quad$ White & $62 \%$ & - \\
African American & $24 \%$ & - \\
Latino & $10 \%$ & - \\
Other & $4 \%$ & - \\
Disease Stage & & - \\
CDC A & $22 \%$ & - \\
CDC B & $44 \%$ & - \\
CDC C & $34 \%$ & - \\
AIDS & $58 \%$ & - \\
\hline \hline
\end{tabular}


tial participants were excluded based on the presence of cognitive impairment that could be attributed to factors other than HIV illness (e.g., brain trauma with loss of consciousness greater than $30 \mathrm{~min}$, other neuromedical comorbidities, active substance abuse or dependence within the last 30 days, or evidence of learning disabilities or schizophrenia).

The cohort included both individuals who were medically asymptomatic, as well as those at more advanced disease stages. Participants were classified using the Centers for Disease Control (1992) HIV Disease Classification, a system that categorizes HIV-infected adolescents and adults based on clinical conditions associated with HIV infection and CD4 T-lymphocyte count. Details regarding CDC stage and AIDS status are also provided in Table 1.

Plasma HIV RNA levels were available for 259 of our participants. Of these, $80(30.9 \%)$ had viral loads in the undetectable range $(\leq \log 2.6)$. For the remaining 179 participants with detectable HIV viral load, their mean plasma HIV viral load level was $\log 4.39(S D=0.95)$. Seventy-two percent $(n=194)$ of the cohort was on some form of an antiretroviral medication regimen as prescribed by their respective primary care providers.

\section{Procedure}

\section{Neuromedical evaluation}

All participants underwent comprehensive neuromedical evaluations, which included: completion of structured clinical data gathering forms; medical and medication use history; neurological and general physical examinations; and laboratory studies including CD4 lymphocyte counts, and routine hematology and chemistry. HIV serological status was determined by enzyme linked immunosorbent assays (ELISA) with Western Blot confirmation.

\section{Mood evaluation}

The presence of depressive symptoms was evaluated with the Beck Depression Inventory (BDI; Beck, 1987), which is a 21-item questionnaire regarding current mood. On average, participants reported a mild level of depressive symptoms as indicated by the BDI total score $(M=10.6, S D=$ 10.4 ), with $28 \%$ reporting depressive symptoms at a level that is generally considered to be clinically significant (greater than or equal to 15 ).

\section{Neuropsychological evaluation}

All participants completed a detailed neuropsychological test battery administered by trained psychometrists. Table 2 summarizes the 4-hr battery, which consists of measures assessing the following seven ability domains: verbal skills, attention/working memory, speed of information processing, learning, memory (delayed recall), abstraction/executive functioning, and motor skills.

Consistent with the recommendations of the NIMH Working Group on Neuropsychological Assessment Approaches in HIV Infection (Butters et al., 1990), each participant's NP test protocol was rated by a senior neuropsychologist (R.K.H.) blinded to HIV serostatus and the participant's performance on the functional measures. The rater was able to remain blinded to HIV serostatus because the charts from the current study did not contain this information and were randomly mixed with those of other studies in which HIV seronegatives were also included. Clinical ratings were determined after converting raw scores on the tests to age-, education- and gender-corrected standard scores (T-scores) using published procedures based upon large normative data sets (Diehr et al., 1998; Gladsjo et al., 1999; Heaton, 1992; Heaton et al., 1991). Clinical ratings of NP function were assigned for each of the seven major ability areas listed in Table 2, using the following 9-point scale: 1 = above average functioning; 2 = average; $3=$ below average $; 4=$ borderline/atypical; 5 = definite mild impairment; $6=$ mild to moderate impairment; $7=$ moderate impairment; $8=$ moderate to severe impairment; 9 = severe impairment. Participants were also assigned a global NP clinical rating using the same scale, with a global rating of 5 or above

Table 2. Neuropsychological test battery arranged by the seven major ability areas

\begin{tabular}{|c|c|}
\hline Verbal & Abstraction/Executive Functioning \\
\hline Boston Naming Test (\# correct $)^{1}$ & Category Test (\# errors) ${ }^{1}$ \\
\hline Thurstone Word Fluency (Correct) ${ }^{1}$ & Trail Making Test $(\text { Part } \mathrm{B})^{1}$ \\
\hline Category Fluency (Animals) ${ }^{2}$ & Attention/Working Memory \\
\hline Information Processing Speed & WAIS-R Digit Span ${ }^{3}$ \\
\hline WAIS-R Digit Symbol ${ }^{3}$ & WAIS-R Arithmetic ${ }^{3}$ \\
\hline Trail Making Test $\left(\right.$ Part A) ${ }^{1}$ & PASAT Total Correct ${ }^{1}$ \\
\hline WAIS-R Block Design ${ }^{3}$ & Learning \\
\hline Motor & Story Learning (points/trials) ${ }^{1}$ \\
\hline Grooved Pegboard Time (dominant hand) ${ }^{1}$ & Figure Learning (points/trials) ${ }^{1}$ \\
\hline Grooved Pegboard Time (non-dominant hand) ${ }^{1}$ & Delayed Recall \\
\hline Finger Tapping (dominant hand) $)^{1}$ & Story Memory ${ }^{1}$ \\
\hline Finger Tapping (non-dominant hand) ${ }^{1}$ & Figure Memory ${ }^{1}$ \\
\hline
\end{tabular}

Note. Normative data taken from the following sources indicated by superscript number: ${ }^{1}$ Heaton et al., 1991; ${ }^{2}$ Gladsjo et al., 1999; ${ }^{3}$ Wechsler, 1981. 
indicating abnormal NP functioning; a global rating in this range required a mild or higher impairment rating on at least two of the seven ability areas (i.e., a single, isolated ability deficit would not qualify for a global rating with the impaired range). The ratings procedure utilized in this study has undergone extensive evaluation, and inter-rater reliability has been found to be excellent. The rationale, nature, reliability and validity of these ratings have been described in detail elsewhere (Heaton et al., 1981, 1994a, 1994b, 1995).

\section{Functional evaluation}

In order to assess the functional relevance of NP impairment, two methodologies were used: (1) objective, laboratory-based measures of capacity to perform tasks that are important in everyday living, and (2) reports of everyday functioning outside of the laboratory (Manifest Functioning). The latter reports ranged from subjective ratings of abilities/disabilities to more readily observable and verifiable facts such as employment status, and assistance received by others in specific aspects of daily living (e.g., financial management). All measures were administered by trained psychometrists. The neuropsychological and functional batteries were administered in a fixed order (functional battery order: Shopping, Financial Skills, Advanced Finances, Medication Management Test-Revised, Cooking, Vocational Assessment).

In the Laboratory assessment, objective levels of IADL functioning were measured using previously established tests, as well as newly created everyday functioning tasks. The Financial Skills (e.g., calculating currency, balancing a checkbook), and Shopping (e.g., selecting items from a previously presented grocery list) measures from the Direct Assessment of Functional Status instrument (DAFS; Lowenstein \& Bates, 1992) were selected as subtests that were expected to be sensitive to cognitive impairment in HIV disease. The DAFS was designed for use with demented, elderly individuals, and the additional measures from that instrument were found to be inappropriate for our population. (For a more detailed description of these DAFS measures, please refer to Lowenstein \& Bates, 1992.) Therefore, new functional measures expected to be both sensitive to the mild NP problems found in HIV, and relevant to the daily functioning of individuals living with HIV, were needed. Two new functional measures that assess areas with which participants in our study commonly reported having difficulty include Advanced Finances and Cooking. These measures are briefly described below.

In Advanced Finances, individuals are asked to pay fictitious bills and manage a fictitious checkbook. They are provided with blank checks, a checkbook register, a check to deposit, deposit slips, three bills to pay and a calculator. They are required to pay each bill and determine their checkbook balance. The most difficult part of this task requires individuals to pay as much of their credit card bill as they can while assuring that they will have $\$ 100$ remaining in their checking account for other needs. Points are awarded for correctly paying each bill, writing checks, filling out the deposit slip, balancing the register, and making sure that there is a final balance of at least $\$ 100$. The task takes approximately 10 minutes to administer and there are 13 possible points. The more basic DAFS Finances and our Advanced Finances tasks were merged into one measure, the Finances task, with a total of 35 points possible.

Medication management ability was evaluated with a revised version of the Medication Management Test (MMT; Albert et al., 1999). The original version of this measure included a "pill dispensing" component and a "medication inference" component. In the former component, participants are observed and scored with respect to their ability to dispense one day's dosage and follow a fictitious prescription regimen, which includes five different mock medications that would be consistent with many of the current therapies that are used in the treatment of HIV. Pill bottles are provided with realistic instructions on standardized labels. As part of this task, participants must transfer the correct number of pills from the pill bottles to a medication organizer designed to hold a 1-week's supply of medication. Participants are scored on the percentage of prescriptions that they correctly place in the organizer (i.e., $0 \%=$ all 5 incorrect to $100 \%=$ all 5 correct.

The "medication inference" component of the original MMT includes 15 items, which require participants to answer questions regarding the five mock medications, as well as one over-the-counter medication insert. Items include information pertaining to how long prescriptions will last, dosage information, and following special instructions, such as taking a medication with or without food. On average, the original MMT takes 15-25 min to administer.

In our modified version, the MMT-Revised (MMT-R) includes only those items which were found to be the most reliable and valid based on pilot work with our participant population, and was criterion-referenced via guidance from an HNRC infectious disease physician and AIDS expert (JAM). The MMT-R retains both components of the original MMT; however, pill dispensing utilized only three of the original five mock medications, and the medication inference component includes seven of the original 15 items. In addition, the inference items are now presented in ascending order of difficulty, some items have been slightly reworded to make them easier to comprehend, and the medication insert was changed in order to provide the information in a more straightforward manner (see the Appendix for the insert). The MMT-R takes approximately $10 \mathrm{~min}$ to administer, and 10 points are possible. The MMT-R task was added to the functional battery after the beginning of the study; therefore, 74 participants did not complete this task.

In the Cooking task, individuals are required to follow recipes and coordinate a meal, and also involve measuring, stirring, and wrapping items. Participants are provided with two recipe cards, one with three cooking steps (pasta) and another that requires only one cooking step (heating bread). The most difficult part of this task asks participants to de- 
termine the order and timing with which to cook the items so that both items are completed at approximately the same time. Points are awarded for following instructions, as well as completing the items at the same time. The task takes approximately $8 \mathrm{~min}$ to administer and there are 30 possible points.

In addition to the above IADL tasks, we utilized information gathered from work histories and a series of objective, criterion-referenced vocational tests as part of the Vocational Assessment. Together, these two types of information can be used to determine whether participants evidence poorer performance on measures of current vocational functioning than would be expected based upon their prior work histories (Heaton et al., 1996).

The U. S. Department of Labor lists 12,855 jobs in the Dictionary of Occupational Titles (DOT; US Department of Labor, 1991a). Each job is assigned a DOT "Worker Qualifications Profile" in which it is rated with regard to the specific levels of all abilities that are required to perform it. These ability requirements include two categories applicable to this study: (1) General Educational Development (GED) is comprised of Reasoning, Mathematics, and Language; and (2) Aptitudes are the more specific abilities required by the job. They include Learning, Verbal, Numerical, Spatial, Form Perception, Clerical Perception, Motor Coordination, Finger Dexterity, Manual Dexterity, EyeHand-Foot Coordination and Color Discrimination.

There are six functional levels for each of the GED abilities and five functional levels for the specific Aptitudes. The functional levels were designed by the Department of Labor in order to rank specific abilities within each GED domain and Aptitude. The Department of Labor then determined the number of jobs within the US economy that require each level for each ability. In general, in the middle functional levels (where most people perform), thousands of jobs are involved. Thus, if a worker's ability drops one level in the middle range (e.g., due to NP impairment), this can suggest that there are many jobs he/she can no longer perform. For a complete explanation, see the Revised Handbook for Analyzing Jobs (US Department of Labor, 1991b) and the Dictionary of Occupational Titles (US Department of Labor, 1991a). One limitation of vocational assessments is that they do not account for experience, so that a person can perform poorly on a novel work sample but perform adequately on job tasks with which she or he has had years of experience. Therefore, experience might reduce the impact on job performance of acquired NP impairment but still result in deficits when measured with standardized vocational tests (Salthouse, 1990, 1994).

Participants completed standardized work samples (MESA SF2) and the next generation COMPASS programs (Valpar International Corporation, 1986, 1992). These batteries consist of multi-modal, criterion-referenced instruments designed to establish participant skill levels in areas related to vocational functioning. The battery takes approximately $1 \mathrm{hr}$ and includes computerized subtests and noncomputerized mechanical tasks that correspond to the previously mentioned DOT Job levels. The computerized tests are comprised of Vocabulary, Reading, Spelling, Mathematics, Language Development (Editing), Problem Solving, Short-term Visual Memory, Shape Discrimination, Size Discrimination, and Placing and Tracking. The mechanical tasks involve Alignment and Driving, Machine Tending and Wiring. Raw scores from these tests are automatically converted into ability levels for each of the DOT classifications using the commercial software accompanying the MESA SF2 and COMPASS. A detailed explanation of test development for the MESA and COMPASS is beyond the scope of this paper (see Valpar International Corporation, 1986, 1992). Briefly, an expert panel assigned to each test item a corresponding ability level. Once the examinee commits a certain number of errors on items at a particular ability level, the subtest is discontinued with the resulting score assigned as the highest ability level before discontinuation. The expert panel also determined minimum ability levels on one or several subtests in order for an examinee to qualify for a functional level within Aptitudes or GED abilities. For example, a person's Spatial Aptitude level depends on his or her obtaining certain ability level scores on the Alignment and Driving, Shape, and Size subtests. All scores on the subtests and on the GED and Aptitudes are completely criterion referenced and are designed for classification according to DOT categories. They are therefore distinct from typical neuropsychological tests measuring similar constructs in that they are not based on normative data but on a specific criterion, and the outcome scores are designed to conform to DOT profile scores rather than standardized scores that might correct for one or more demographic variables. For the purposes of this paper, the functional levels for the Aptitudes and GED abilities were summed in order to calculate a Work Assessment Total Score to provide an overall index of vocational ability (Heaton et al., 1996).

Manifest Functioning is defined as self-report of everyday functioning outside of the laboratory. Participants were asked to complete two questionnaires regarding their current level of everyday functioning. The Patient's Assessment of Own Functioning Inventory (PAOFI; Chelune et al., 1986) is a 41-item questionnaire in which the participant reports the frequency with which he/she has difficulties with memory, language and communication, use of his/her hands, sensory-perception, higher level cognitive and intellectual functions, work and recreation. This instrument focuses on cognitive symptoms, and is used by HNRC clinicians in their determination of an AAN diagnosis of syndromic versus subsyndromic NP impairment (i.e., "subsyndromic" impairment does not appear to interfere with the patient's everyday functioning).

Most of the participants $(n=251)$ also completed a modified version of the Lawton and Brody (1969) IADL scale, which includes 13 items detailing the degree to which they independently function in the areas of Financial Management, Home Repair, Medication Management, Laundry, Transportation, Grocery Shopping, Comprehension of Reading/TV Materials, Shopping, Housekeeping (Clean- 
ing), Cooking, Bathing, Dressing, and Telephone Use. For each activity the participant separately rates his/her current level of independence and highest previous level of independence. The total score is the total number of activities for which there is currently a need for increased assistance (ranging from minimal to complete assistance), with a range of zero (no change) to 13 (increased dependence in all activities). By examining the distributions of 168 NPnormal participants on this scale, it was determined that increased dependence on two or more of the 13 areas of functioning is relatively rare in this population (i.e., it occurred in fewer than $15 \%$ of cases). Therefore, we used a cut-off score of 2 as our criterion for overall IADL dependence.

\section{Statistical analyses}

Using the entire sample, Cronbach's alpha reliability coefficients were calculated for the three newly developed or revised functional measures, in order to assess the internal reliability of these instruments. Participants were then organized into two groups based on their global NP ratings, as NP-normal (ratings of 1-4) and NP-impaired (ratings of 5-9). To compare initial characteristics and performance on the functional assessment between groups, chi-square test for proportions, $t$ tests, and analysis of variance (ANOVA) were used. Correlational analyses assessed the relationships between NP functioning (based on clinical ratings) and performance on certain laboratory functional measures. Nominal logistic regressions were used to determine which NP ability deficits were most predictive of failures in the laboratory-based functional measures. Linear and logistic regression analyses also were performed in order to evaluate unique contributions of NP status, the Functional Deficit Score (see below), medical variables and depressed mood (BDI) as potential predictors of three functional outcome measures: cognitive complaints, IADL dependence, and employment status. Bonferroni corrections were applied to address alpha inflation due to multiple comparisons. As mentioned above, ROC curve analyses and likelihood ratios will be used to evaluate the probabilities of increased dependence in everyday living, based on performance on our functional test battery. Details of these methods are beyond the scope of the current paper, but can be readily found in the literature (e.g., Woods et al., 2003; Zweig \& Campbell, 1993).

A Functional Deficit Score (FDS), based upon all of the functional measures, was formulated to reflect overall impairment on the laboratory based functional battery. Similar to procedures previously used to characterize NP impairment (Heaton et al., 1995), deficit scores $(0=$ normal to $5=$ severe impairment), were derived for each of the functional measures based on the performance and percentile ranks of 168 NP-normal participants on the functional assessment. As with classifications of T-score ranges in NP tests (Heaton et al., 1991, 1992), a cut-off of $1 S D$ below the mean of normals defines the range most likely to reflect normal performance, and $0.5 S D$-wide ranges lower than that define mild (deficit score $=1$ ), mild-to-moderate (2), moderate (3), moderate-to-severe (4) and severe (5) impairment. After these cut-offs were derived, the research team qualitatively reviewed the functional protocols of participants who obtained deficit scores greater than zero. For each functional measure it was determined that performances statistically classified as impaired actually did reflect inadequate performance of the IADL task in question (e.g., serious errors in medication management, failure to produce a "palatable" meal, failures in paying bills and/or allowing for specified financial needs). Thus, functional tests or FDS performances above the 15th percentile of the normative sample were considered normal (deficit score $=0$ ), and increasingly worse test raw scores were assigned deficit scores between 1 and 5 . A separate $0-5$ deficit score was assigned for MMT-R, Cooking, Finances, DAFS Shopping, and Work Assessment. These individual deficit scores were then averaged to create the FDS summary score. The FDS can be considered as a continuous variable or, again using the $15 \%$ cutoff from the 168 NP-normal participants, it can be used to classify participants as impaired (FDS > 0.50 ) or normal (FDS $<0.51$ ) on the functional battery.

Since the MMT-R task was added to the functional battery following the inception of the study, 74 study participants did not complete this measure. Therefore, a prorated FDS was calculated for all participants who did not complete the MMT-R task. Descriptive, chi-square, and correlational analyses revealed that this prorated FDS could be used without a significant loss of validity to the measure. For those participants with both an FDS and Prorated FDS $(n=193)$, the means and standard deviations of the two measures were virtually the same (FDS: $M=0.56, S D=$ 0.75 ; prorated FDS: $M=0.52, S D=0.73$ ); there was overall agreement in rate of functional impairment between the measures ( specificity $=92 \%$; sensitivity $=100 \%$; classification accuracy $=94 \%$ ); and the two measures were very strongly correlated with one another $(r=.97, p<.00001)$. Therefore, for the following statistical analyses, the prorated FDS will be used as the FDS for those 74 participants who did not complete the MMT-R task.

\section{RESULTS}

Among the $267 \mathrm{HIV}+$ study participants, 168 were classified as NP-normal and 99 as NP-impaired; level of impairment was rated as mild in 60 participants, mild-to-moderate in 34 , and moderate in 5 participants. The most prevalent deficits among the NP-impaired individuals were in ability domains of Learning (68\%), Abstraction/Executive functioning (54\%), Attention/Working Memory (53\%), and Motor Functioning (47\%). The least prevalent ability deficits for the NP-impaired group were Speed of Information Processing (36\%), Verbal Functioning (27\%), and Delayed Recall $(25 \%)$. NP-impaired individuals averaged somewhat less education, and were more immunosupressed, and more likely to be unemployed and non-White (see Table 3). 
Table 3. Comparison of NP-normal and NP-impaired groups on demographic and disease variables

\begin{tabular}{lcccccccc}
\hline \hline \multirow{2}{*}{ Variable } & \multicolumn{2}{c}{ NP-Normal } & & \multicolumn{2}{c}{ NP-Impaired } & & \\
\cline { 2 - 3 } Age & $M$ or $P$ & $S D$ & & $M$ or $P$ & $S D$ & $\mathrm{t} / \chi^{2}$ & $p$ \\
Education & 39.3 & 7.5 & 39.4 & 6.5 & -0.08 & .9 \\
CD4 & 13.6 & 2.4 & 12.9 & 2.3 & 2.4 & .02 \\
Percent male & 386 & 285 & 305 & 224 & 2.6 & .01 \\
Ethnicity (percent) & 85.7 & - & 79.8 & - & 1.5 & .2 \\
$\quad$ & & & & & & \\
$\quad$ White & 70.8 & - & 45.5 & - & 16.8 & $<.001$ \\
$\quad$ African American & 17 & - & 37 & - & - & - \\
$\quad$ Hispanic & 9 & - & 11 & - & - & - \\
$\quad$ Other & 4 & - & 6 & - & - & - \\
Percent AIDS & 56.0 & - & 61.6 & - & 0.8 & .4 \\
Percent CD4 $<200$ & 27.4 & - & 38.4 & - & 3.5 & .06 \\
Percent employed & 36.8 & - & 11.6 & - & 21.0 & $<.001$ \\
\hline \hline
\end{tabular}

Note. $\mathrm{NP}=$ Neuropsychologically. $n=168$ for NP-Normal, $n=99$ for NP-Impaired.

\section{Reliability and Distribution Characteristics of New/Revised Functional Measures}

Table 4 summarizes the results of reliability analyses and the range of scores for each of our newly developed or modified functional measures. The Cronbach's alpha coefficients for the new measures reveal generally adequate internal reliability (.66 to .82). Considering that these are everyday tasks that most adults are expected to perform, it is not surprising that a sizeable minority of HIV+ participants performed at ceiling. Nevertheless, the score ranges in Table 4 also show that the total group evidenced considerable variability in performance on these measures.

\section{NP Status and Laboratory Measures of IADLs}

Table 5 presents the results of one-way ANOVAs, effect sizes and confidence intervals for comparisons of the NP-

Table 4. Participant performance characteristics and internal reliability of newly developed/modified functional measures

\begin{tabular}{lccc}
\hline \hline Variable & Cooking & Finances & MMT-R \\
\hline$N$ & 267 & 266 & 193 \\
Possible range & $0-30$ & $0-35$ & $0-10$ \\
Actual range & $11-30$ & $17-35$ & $1-10$ \\
$M$ & 26.6 & 32.5 & 8.2 \\
$S D$ & 4.4 & 3.0 & 2.1 \\
Test reliability (Cronbach's $\alpha)$ & .66 & .82 & .72 \\
Percent at ceiling & & & \\
$\quad$ Entire sample & 42 & 13 & 43 \\
$\quad$ NP-normal & 51 & 15 & 61 \\
$\quad$ NP-impaired & 25 & 8 & 16 \\
\hline \hline
\end{tabular}

Note. MMT-R = Medication Management Test-Revised. NP = Neuropsychologically. normal and NP-impaired groups on the FDS and the individual functional ability measures. As the table indicates, NP-impaired participants performed significantly worse on the FDS and each of the functional measures, compared to NP-normal participants (all $p \mathrm{~s}<.0001$ ). Effect sizes for the FDS and all individual functional measures were large, ranging from 0.71 (Cooking) to 1.42 (FDS). The FDS and Work Assessment had the largest effect sizes, and the confidence intervals indicate that they were significantly larger than those found for two of the other functional measures (e.g., Cooking and Shopping).

As Figure 1 illustrates, NP-impaired participants demonstrated a significantly higher rate of global functional impairment (based on the FDS) compared to NP-normal participants [67\% vs. $\left.15 \% ; \chi^{2}(1)=73.10, p<.0001\right]$, and NP-impaired participants were also significantly more likely to fail on every domain of functional ability, including Work Assessment $\left[\chi^{2}(1)=62.40, p<.0001\right]$, Finances $\left[\chi^{2}(1)\right.$ $46.92, p<.0001]$, Medication Management $\left[\chi^{2}(1) 32.87\right.$, $p<.0001]$, Cooking [ $\left.\chi^{2}(1)=24.82, p<.0001\right]$, and Shopping $\left[\chi^{2}(1) 12.86, p<.0003\right]$, with the rates of functional impairment being highest in the areas of Work, Finances, and Medication Management. All comparisons remained statistically significant following Bonferroni correction ( $p=$ .006).

It is possible that some of the above mentioned findings could be confounded by participants' lack of familiarity with certain skills (e.g., using a checkbook and cooking). However, post hoc analyses revealed that lack of familiarity was a rare occurrence, at least with regard to use of a checkbook and cooking. A majority (248) of the participants were asked whether they currently use a checking account, and for those who did not currently have a checking account, they were asked if they had previously had a checking account. Seventy-four percent $(n=182)$ of the sample currently used a checkbook, and of those 66 participants who did not currently use a checkbook, the majority $(n=55)$ had independently used a checkbook in the past. Therefore, a total of 237 of the 248 participants (96\%) with available data had currently or previously used a checkbook in their daily lives. Of the 11 participants who had never used a checkbook, 10 of these were NP-impaired and were less educated than participants who had experience with using checkbooks [years of education $M=11.36, S D=$ 1.75 vs. $M=13.88, S D=2.41 ; t(246)=-2.75, p<.01]$. With regard to the Cooking task, 264 participants were asked whether they currently or had previously cooked independently. At the time of the assessment, $83 \%$ of the participants $(n=219)$ reported that they currently cooked, and of the 45 participants who reported that they did not currently cook, most $(n=33)$ reported that they had cooked previously. Thus, $95 \%$ of this large subsample had current or previous cooking experience.

Post-hoc analyses were also conducted to evaluate whether there were any differences in overall functional ability (FDS) based on demographic or disease-related variables in the NP-normal group. Bivariate analyses revealed that, among 
Table 5. Comparisons of Neuropsychologically (NP) normal and NP-impaired $\mathrm{HIV}+$ groups on the Functional Deficit Score ${ }^{\mathrm{a}}$ (FDS) and individual functional measures

\begin{tabular}{|c|c|c|c|c|c|c|c|}
\hline \multirow[b]{2}{*}{ Measure } & \multicolumn{2}{|c|}{ NP-Normal } & \multicolumn{2}{|c|}{ NP-Impaired } & \multirow[b]{2}{*}{$F^{* *}$} & \multirow{2}{*}{$\begin{array}{l}\text { Effect } \\
\text { size }\end{array}$} & \multirow{2}{*}{$\begin{array}{c}\text { Confidence } \\
\text { interval }\end{array}$} \\
\hline & $M$ & $S D$ & $M$ & $S D$ & & & \\
\hline FDS $*$ & 0.22 & 0.37 & 1.07 & 0.186 & 124.63 & 1.42 & $1.14,1.69$ \\
\hline Work Assessment & 36.86 & 6.26 & 28.15 & 7.03 & 110.02 & 1.33 & $1.05,1.60$ \\
\hline MMT-R & 9.08 & 1.46 & 6.88 & 2.26 & 67.33 & 1.21 & $0.89,1.52$ \\
\hline Finances & 33.39 & 1.75 & 30.94 & 3.91 & 49.36 & 0.89 & $0.63,1.15$ \\
\hline Shopping & 16.48 & 2.20 & 14.74 & 2.50 & 35.46 & 0.75 & $0.49,1.01$ \\
\hline Cooking & 27.73 & 3.54 & 24.76 & 5.12 & 31.19 & 0.71 & $0.45,0.96$ \\
\hline
\end{tabular}

Note. $\mathrm{NP}=$ Neuropsychologically. FDS $=$ Functional Deficit Score. MMT $-\mathrm{R}=$ Medication Management Test-Revised. $N=168$ for NP-normal, $N=99$ for NP-impaired, except MMT-R, where $N=116$ for NP-normal and $N=77$ for NP-impaired.

*Higher FDS scores represent more severe global functional impairment.

$* *$ All $p$ s $<.0001$.

the NP-normal group, there were no significant differences in FDS failure rates associated with demographic or diseaserelated variables [e.g., ethnicity: $\chi^{2}(1)=2.4$; sex: $\chi^{2}(1)=$ 0.6 ; age: $t(166)=-1.6$; education: $t(166)=1.5$; CD4 count: $t(166)=-0.9 ; p \mathrm{~s}>.1$ in all instances]. A similar pattern was observed within the NP-impaired group except that there was a greater percentage of non-White participants showing FDS failure $\left[\chi^{2}(1)=11.1, p<.001\right]$. Analysis of failure rates within the NP-impaired group on specific functional tests revealed a significant difference between White and non-White participants only on the Work Assessment $\left[\chi^{2}(1)=13.6, p<.001\right]$. On this assessment, the NP-impaired White participants obtained higher scores than non-White participants $[t(97)=-2.9, p<.01]$, but White participants also obtained higher scores on estimates of premorbid work functioning based on the COMPASS software analyses of work histories $[t(96)=-2.4, p<.02]$. When a difference score was calculated between current and pre- morbid work ability scores, there was no significant difference between White and non-White participants $[t(96)=$ $-0.5, p>.5$ ], suggesting that the decline from premorbid functioning was comparable for both White and non-White participants.

Next we conducted a series of nominal logistic regressions to determine which NP abilities seemed most important in determining success or failure on the functional measures. Using scores on the seven NP domains as potential predictors, significant $(p<.0001)$ omnibus models were found for the criterion impairments on the FDS $\left[\chi^{2}(7)=151.51, R^{2}=.44\right]$, Work Assessment $\left[\chi^{2}(7)=\right.$ $\left.135.42, R^{2}=.41\right]$, Medication Management $\left[\chi^{2}(7)=59.55\right.$, $\left.R^{2}=.25\right]$, Finances $\left[\chi^{2}(7)=73.24, R^{2}=.22\right]$, Cooking $\left[\chi^{2}(7)=41.37, R^{2}=.14\right]$, and Shopping $\left[\chi^{2}(7)=26.96\right.$, $\left.R^{2}=.11\right]$. Only four NP ability areas were identified as uniquely contributing to the prediction of impairment on two or more of the functional measures: Abstraction/

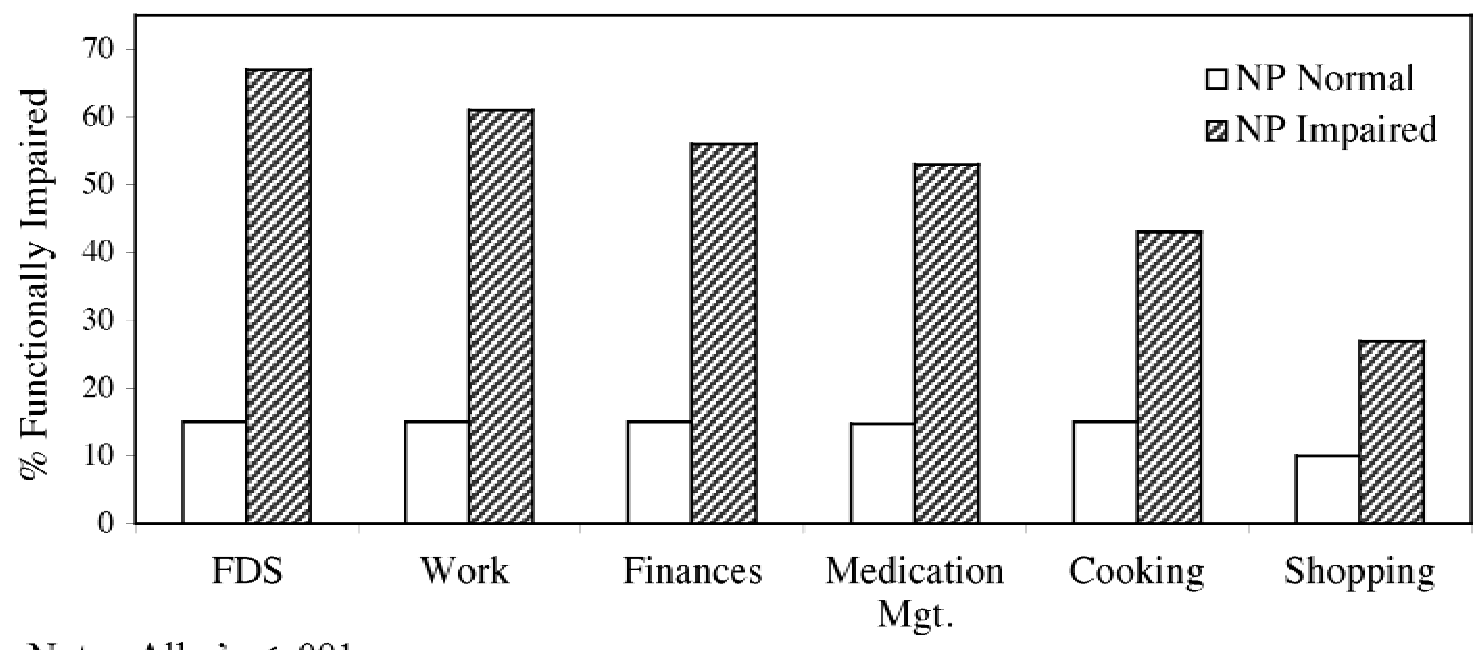

Note: All $p$ 's $<.001$

Fig. 1. Rate of functional impairment by neuropsychological status. 
Executive Functioning predicted failures on the FDS, Work Assessment, Finances and Medication Management; Learning predicted failures on Medication Management, Shopping and Cooking; and Verbal function and Attention/ Working Memory each significantly predicted failure on the FDS and Work Assessment.

Two work profiles were generated for each participant based upon (1) current vocational functioning using the standardized work samples (i.e., Work Assessment Total Score) and (2) estimated maximum level of prior functioning using standard analyses of work histories. As noted above (Table 5), NP-impaired participants performed significantly worse than those who were NP-normal on the Work Assessment $(p<.0001)$. A Pearson correlational analysis also indicated that NP global functioning (i.e., the global clinical NP rating) was strongly associated with the Work Assessment Total Score $(r=-.65, p<.0001)$. Participants' estimated previous levels of vocational functioning (based upon scores derived from work histories) were then evaluated based on NP status. Results of a one-way ANOVA suggested that the NP-impaired group had lower baseline levels of vocational functioning compared to their NPnormal counterparts $[M=37.94, S D=6.08, v s . M=40.71$, $S D=5.62 ; F(1,263)=14.04, p<.001]$. Therefore, the discrepancies between participants' expected (estimated prior) levels of functioning and currently observed levels (based upon the Work Assessment Total Score) were analyzed. A negative discrepancy score suggests that participants' vocational functioning is worse at the time of assessment than it has been in the past. The results of a one-way ANOVA demonstrated that the mean discrepancy between expected versus current level of vocational functioning was significantly greater for the NP-impaired group compared to the NP-normal group $[M=-9.69, S D=7.75$, vs. $M=-3.90, S D=7.71 ; F(1,263)=34.50, p<.0001]$.

\section{Manifest Functioning in Everyday Life}

A series of bivariate analyses showed that both the FDS and NP status (global clinical rating) were significantly related to measures of reported everyday functioning, including complaints of cognitive difficulties (PAOFI), degree of independence in completing IADLs at home, and employment status. Of greater interest, however, is whether FDS and NP status make unique contributions to such predictions, when effects of biological markers of disease progression (AIDS status and CD4 count) and depression (Beck Depression Inventory) are also considered. Therefore, we performed multivariate analyses to address these questions.

\section{Cognitive complaints}

Table 6 summarizes a linear multiple regression analysis, in which the criterion of interest was cognitive complaints (PAOFI Total). The model was significant, and accounted for approximately $38 \%$ of the variance in participants' cognitive complaints $\left[R^{2}=.38, F(5,235)=28.73, p<.0001\right]$.
Table 6. Linear multiple regression model predicting participants' cognitive complaints (Patient's Assessment of Own Functioning Inventory Total Score) by neuropsychological (NP) status, Functional Deficit Score, AIDS status, immunosuppression, and Beck Depression Inventory

\begin{tabular}{llcc}
\hline \hline $\begin{array}{l}\text { Criterion } \\
\text { variable }\end{array}$ & \multicolumn{1}{c}{ Predictor variable } & $\begin{array}{c}\text { Beta } \\
\text { coefficient }\end{array}$ & $p$ \\
\hline PAOFI & Global NP Clinical Rating & .09 & .18 \\
& Functional Deficit Score & .28 & $<.0001$ \\
& AIDS Status & .03 & .61 \\
& CD4 Count & .03 & .66 \\
& BDI Total & .46 & $<.0001$ \\
\hline \hline
\end{tabular}

Note. $N=241$. PFI $=$ Patient's Own Assessment of Functioning. BDI $=$ Beck Depression Inventory.

Global functional impairment (FDS) and depressive symptomatology each significantly and uniquely contributed to the model, while NP functioning and biological markers (CD4 and AIDS status) did not. Post-hoc Pearson correlations revealed that higher levels of functional impairment and depression were associated with a high number of cognitive complaints (respectively, $r=.38$, and $r=.48, p$ s $<$ .0001). Of note, the BDI Total Score and FDS were not significantly associated with each other $(r=.10, p>.05)$.

\section{IADL dependence}

Based on 251 participants' patterns of responses on the IADL questionnaire, 209 (83.3\%) of them were deemed IADLindependent and 42 met criteria for IADL-dependence (criteria reviewed in the Methods section). The independent group reported dependence on an average of only 0.38 ( $S D=$ 0.68 ) of the 13 IADL tasks; by contrast, the dependent participants reported less independence in an average of 5.02 $(S D=3.53)$ IADL activities. IADL-dependent participants reported the highest rates of dependence in the areas of Home Repair, Laundry, Grocery Shopping, Comprehension of Reading/TV material, Shopping, and Cooking. Chisquare analyses revealed that the IADL-dependent participants required significantly more assistance in all domains of activities of daily living (all $p$ s $<.0001$ ) compared to IADL-independent participants, and all comparisons remained statistically significant following Bonferroni correction $(p=.004)$.

Table 7 presents the results of a nominal logistic regression analysis, in which we input the same list of diseaserelated, depression and performance-based variables in an effort to predict IADL status (independence $v s$. dependence). Again the model was significant $\left[R^{2}=.24 ; \chi^{2}(5)=\right.$ 54.23, $p<.0001]$. Three variables provided significant, unique contributions to the prediction model: NP performance, the FDS and depressed mood. Post-hoc $t$ tests revealed that, compared to IADL independent participants, those who were dependent had significantly higher (worse) 
Table 7. Nominal logistic regression model predicting IADL dependence by neuropsychological (NP) status, Functional Deficit Score, AIDS status, immunosuppression and depressive symptoms

\begin{tabular}{llcc}
\hline \hline $\begin{array}{l}\text { Criterion } \\
\text { variable }\end{array}$ & \multicolumn{1}{c}{ Predictor variable } & $\chi^{2}$ & $p$ \\
\hline IADL & Global NP Clinical Rating & 5.01 & .03 \\
Dependence & Functional Deficit Score & 4.67 & .03 \\
& AIDS Status & 0.37 & .5 \\
& CD4 Count & 0.14 & .71 \\
& BDI Total & 25.63 & $<.0001$ \\
\hline \hline
\end{tabular}

Note. IADL $=$ Instrumental Activities of Daily Living. BDI $=$ Beck Depression Inventory. $N=250$.

global NP ratings $[M=4.81, S D=1.09$, vs. $M=3.63$, $S D=1.48 ; t(249)=-4.90, p<.0001]$, worse FDS scores $[M=0.94, S D=0.85$, vs. $M=0.41, S D=0.64 ; t(249)=$ $-4.57, p<.0001]$, and higher BDI total scores $[M=17.55$, $S D=10.36$, vs. $M=8.46, S D=7.53 ; t(248)=-6.67$, $p<.0001]$. Table 8 presents the rates of impairment on laboratory-based functional measures for the IADL dependent and independent groups. Chi-square analyses indicate that the IADL-dependent group showed higher impairment rates on all functional measures except shopping.

Because both NP functioning and FDS were significant predictors of IADL dependence status, additional analyses were performed to illustrate how the two laboratory-based measures might be used together in clinical decision making. Figure 2 presents the results of an ROC curve analysis in which FDS values were used to evaluate the likelihood of IADL dependence; the results were statistically significant $(A U C=0.73, S E=0.04, p<.0001 ; C I=0.65,0.81)$.

Table 9 summarizes the utility of various FDS cut-points in predicting IADL dependence. For demonstration purposes we chose a cut-point of 0.45 (very close to the cutpoint used to define FDS "impairment") as providing a reasonable balance between sensitivity (.64) and specificity (.71). Similar analyses were performed using the NP global

Table 8. Comparison of IADL-dependent and IADL-independent groups on percent impaired on functional measures

\begin{tabular}{lcccc}
\hline \hline Test & $\begin{array}{c}\text { IADL- } \\
\text { independent }\end{array}$ & $\begin{array}{c}\text { IADL- } \\
\text { dependent }\end{array}$ & $\chi^{2}$ & $p$ \\
\hline Work Assessment & 24 & 60 & 18.9 & $<.0001$ \\
MMT-R & 26 & 44 & 3.8 & .05 \\
Finances & 26 & 43 & 4.7 & .03 \\
Shopping & 13 & 21 & 1.7 & .20 \\
Cooking & 19 & 48 & 14.5 & .0001 \\
Functional Deficit Score & 29 & 64 & 18.6 & $<.0001$ \\
\hline \hline
\end{tabular}

Note. IADL $=$ Instrumental Activities of Daily Living. MMT-R = Medication Management Test-Revised. $N=209$ for ADL-independent, $N=42$ for ADL-dependent.

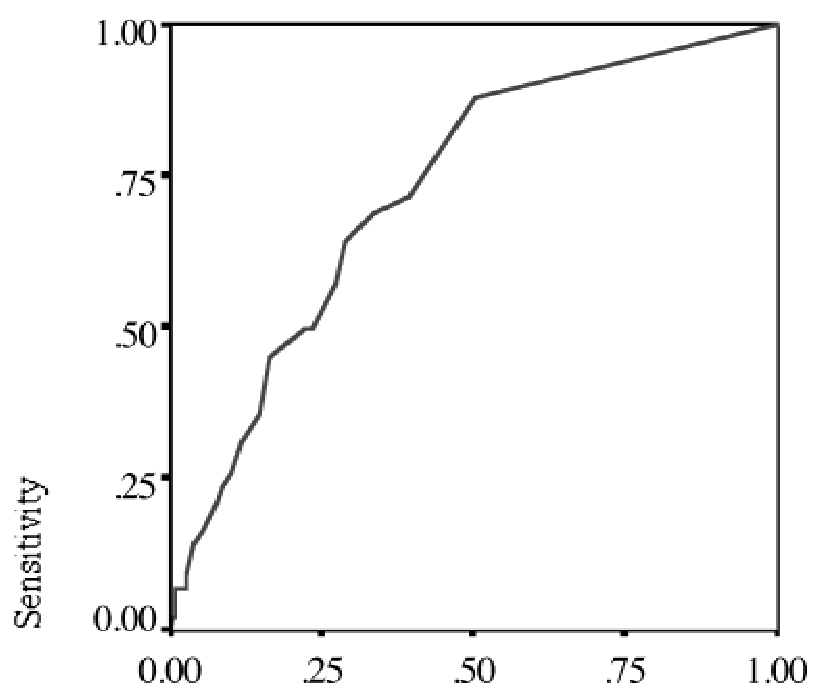

\section{1 - Specificity}

+Note: Diagonal segments are produced by ties.

Fig. 2. ROC Curve: Global functional impairment (FDS) predicting presence or absence of IADL dependence.

ratings as predictors; although not shown here, the ROC analysis was again highly significant $(A U C=0.73, S E=$ $.04, p<.0001 ; C I=0.66,0.80$ ), and a cut-point of $>4$ (the definition of NP impairment) provided optimal sensitivity (.64) versus specificity (.70).

Table 9. Diagnostic characteristics of Functional Deficit Score (FDS) cut-scores for prediction of Independent Activities of Daily Living (IADL) dependence

\begin{tabular}{cccc}
\hline \hline FDS cut-score & Sensitivity & Specificity & Likelihood Ratio \\
\hline 0.10 & .88 & .50 & 1.75 \\
0.23 & .71 & .61 & 1.82 \\
0.33 & .69 & .67 & 2.06 \\
0.45 & .64 & .71 & 2.24 \\
0.55 & .57 & .73 & 2.09 \\
0.68 & .50 & .77 & 2.14 \\
0.78 & .50 & .78 & 2.27 \\
0.90 & .45 & .84 & 2.77 \\
1.10 & .36 & .85 & 2.41 \\
1.23 & .31 & .86 & 2.70 \\
1.33 & .26 & .90 & 2.62 \\
1.45 & .24 & .91 & 2.77 \\
1.55 & .21 & .92 & 2.78 \\
1.70 & .17 & .95 & 3.15 \\
1.90 & .142 & .96 & 3.76 \\
2.10 & .10 & .97 & 3.28 \\
2.23 & .07 & .97 & 2.45 \\
2.78 & .07 & .99 & 7.10 \\
2.90 & .024 & .99 & 2.40 \\
3.20 & .024 & .99 & 4.80 \\
4.40 & .000 & - & - \\
\hline \hline
\end{tabular}


Figure 3 shows that, of the 134 participants who scored below the proposed cutoffs (i.e., performed normally) on both the FDS and NP global rating, only 5.2\% were dependent in their IADLs. By contrast, impairment on either predictor (NP or functional) was associated with greater than a 5 -fold increase in the likelihood of dependence. Note that the 58 participants who were impaired on just one of the performance-based predictors would be much more likely to be misclassified if only the other (NP or functional) battery had been used alone.

\section{Employment status}

Lastly, employment status was evaluated. A chi-square analysis revealed that the NP-impaired group was significantly more likely to be unemployed compared to their NPnormal counterparts [88\% vs. $\left.63 \% ; \chi^{2}(1)=21.0, p<.0001\right]$. Table 10 shows the results of a nominal logistic regression analysis to predict employment status (employed vs. unemployed), again using the two performance-based measures (NP and FDS status), depression, and measures of disease progression as the independent variables. The model was significant $\left[R^{2}=.24, \chi^{2}(5)=72.31, p<.0001\right]$, and three measures contributed uniquely: FDS, AIDS status and depressed mood. Follow-up analyses revealed that, compared to their employed counterparts, unemployed participants were more likely to have AIDS [65\% vs. $42 \% ; \chi^{2}(1)=$ $11.12, p<.001]$, as well as higher levels of global functional impairment [FDS; $t(256)=-3.89, p<.0001]$ and depression [BDI Total; $t(255)=-5.77, p<.0001$ ].

\section{DISCUSSION}

This study supports and extends previous reports regarding the everyday life significance of NP impairments associated with HIV infection (Albert et al., 1995; Heaton et al., 1996; Hinkin et al., 2002; Marcotte et al., 1999; Stern et al., 1991). It is the largest such study to date and the most comprehensive in its coverage of both performance-based measures of IADLs and manifest measures of daily functioning outside of the laboratory. The laboratory measures
Table 10. Nominal logistic regression model predicting employment by measures by neuropsychological (NP) status, Functional Deficit Score, AIDS status, immunosuppression, and depressive symptoms

\begin{tabular}{llcl}
\hline \hline Criterion variable & \multicolumn{1}{c}{ Predictor variable } & $\chi^{2}$ & \multicolumn{1}{c}{$p$} \\
\hline Employment & Global NP Clinical Rating & 0.60 & .44 \\
& Functional Deficit Score & 6.30 & .01 \\
& AIDS Status & 8.94 & $<.01$ \\
& CD4 Count & 1.27 & .26 \\
& BDI Total & 22.32 & $<.0001$ \\
\hline \hline
\end{tabular}

Note. BDI $=$ Beck Depression Inventory. $N=257$.

cover a variety of tasks relevant to everyday living, ranging from relatively basic skills (shopping and cooking) to more demanding activities (vocational functioning).

The newer laboratory-based measures of IADLs introduced here were found to have adequate internal consistency reliability (Table 5). Moderate ceiling effects were expected on these measures, especially since the majority of our participants were NP-normal, but participants who did have NP impairment evidenced a range of IADL performance problems. Thus, the functional battery was able to demonstrate excellent concurrent validity with NP testing: NP impairment was associated with much higher rates of failure on each of the laboratory based functional measures (Figure 1).

It is unlikely that demographic variables, rather than HIV infection, explained impaired performance on tests of everyday functioning. FDS was not significantly associated with age, gender, or ethnicity among the NP-normal group. Similar findings were obtained in the NP-impaired group with respect to age, gender, and education. Although nonWhite participants in this group were more likely to be impaired on the Vocational Assessment (but not other functional measures), this appeared to be due to lower premorbid vocational functioning rather than acquired functional impairment. That is, according to COMPASS analysis of work histories, they demonstrated lower levels of pre-

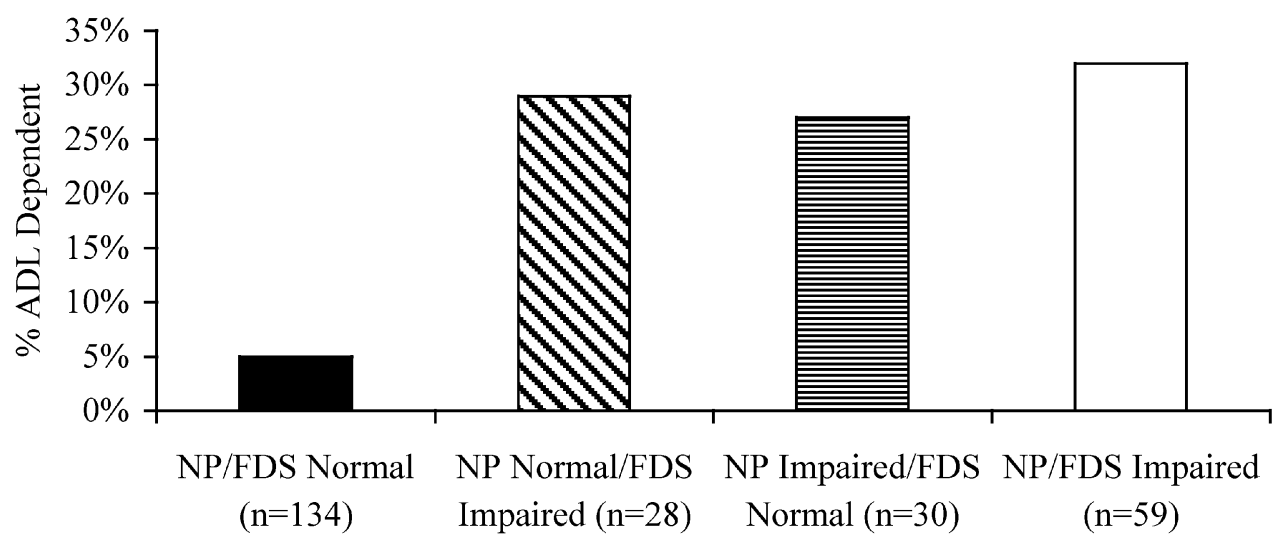

Fig. 3. Rate of IADL dependence by neuropsychological and functional impairment status. 
morbid vocational functioning. When this difference was controlled, the ethnicity effect on current vocational functioning was not significant.

Most of our participants had reported significant current and/or past everyday experience with the types of tasks measured here (i.e., checkbook balancing, cooking). Thus, the high rate of impairment on tests of everyday functioning among the NP-impaired participants probably cannot be explained on the basis of lack of relevant experience.

The question of which NP abilities are essential for specific everyday tasks is interesting and potentially important in clinical decision-making. In general, if a person shows NP impairment on tests of a certain ability, he/she would be considered at risk for failure in everyday tasks that require the same ability (Heaton \& Pendleton, 1981). Perhaps not surprisingly, we found that the NP deficits which best predicted failures on standardized tests of IADLs, were those that also are most commonly observed among cognitively impaired HIV+ participants. Specifically, problems with Learning, Abstraction/Executive Function, and Attention/ Working Memory, which would be consistent with involvement of frontostriatal brain systems, accounted for most of the unique variance in predictions of individual IADL failures and failure on the total functional battery (FDS). Although it makes sense that, for example, learning deficits uniquely contribute to the prediction of problems with medication management, shopping and cooking, it is important to recognize that learning deficits rarely occur in isolation within the HIV infected population. Also, IADLs themselves involve multiple cognitive abilities, and may be failed equally by people who have different patterns of NP deficits. Nevertheless, our results suggest that impairments in the above three ability domains are particularly likely to be associated with problems in everyday functioning of HIV infected adults.

Our measures of manifest everyday functioning ranged from subjective experience of cognitive difficulties (PAOFI), to presumably less subjective reports of how independently IADLs are actually being performed, and still more objectively observable employment status. NP testing still predicts employment status when included in a model alone, but is not significant when functional measures are added (Table 10). However, performance on the functional battery (FDS) uniquely contributed to the prediction of all three of these manifest indicators of everyday functioning, even when NP testing and measures of HIV disease progression were also being considered in the multivariate prediction models. This suggests that performance based functional measures of the sorts used in our study may compliment NP testing in determining whether HIV infected persons suffer from "syndromic" neurocognitive conditions such as minor cognitive-motor disorder.

Figure 3 illustrates the finding that impairment on either NP testing or functional testing (or both) is associated with a substantial $(5+$ fold $)$ increase in risk for IADL dependence. It must be acknowledged, however, that more than half of our participants who were impaired on standardized ability testing claimed to be fully independent in their IADLs. One likely reason for this is that our total participant sample is relatively healthy (e.g., all were ambulatory and only one-third had even a history of an AIDS defining illness), and only $37 \%$ evidenced any kind of NP impairment. The associated very low prevalence of IADL dependence in this sample $(16.7 \%)$ makes for a challenging prediction problem, whereas in populations having higher base rates of dependence the positive predictive value of results on standardized ability tests will ostensibly improve (Baldessarini et al., 1983). In fact, higher rates of dependence would be expected in other HIV + groups, such as those with more advanced illness and among clinical referrals with specific concerns about IADL dependence.

Of particular importance for HIV infected persons is their ability to manage complex medication regimens: Although the availability of powerful new drug combinations (highly active antiretroviral treatments) offers the potential to extend both the duration and quality of life, they require the patient to understand and follow detailed instructions about the proper timing and dosage of multiple drug administrations throughout each day. Our revision of the Medication Management Test (Albert et al., 1999) was designed to efficiently tap these abilities. As expected, NP impairment was associated with poor performance on laboratory-based measures of IADLs, including medication management. However, a limitation of the current study is that it did not include a measure of participants' accuracy in following their own antiretroviral medication regimens. For example, Hinkin et al. (2002) have used electronic monitoring technology (MEMS caps) to track medication use in HIV infected adults, and found that those who were NP-impaired evidenced worse adherence to their prescribed regimens. Future research with laboratory based medication management tasks should seek to validate them using MEMS caps or other objective methods of assessing adherence.

Because this is a cross sectional study, our prediction models are strictly correlational and are unable to prove cause-effect relationships. Nevertheless, it makes sense that impairments demonstrated on laboratory based tests of impairments in NP and functional abilities are likely to cause affected individuals to experience difficulties in their everyday functioning. This is especially true for standardized tasks that were designed to mimic essential activities of daily living. On the other hand, the causal significance of depressed mood in our prediction models of manifest everyday functioning is open to question: For example, depressed mood might contribute to disability, or depression might only bias (negatively) participants' perceptions and reports of their everyday functioning. There are two reasons to suspect that depression is indeed a source of disability in this population. The first is the fact that the BDI total score made very significant contributions to the prediction of both subjective and objective indicators of everyday functioning in this study, whereas biased perceptions would be most likely to influence subjective experiences (i.e., the PAOFI; Chelune et al., 1986). Second, the BDI contribution 
to prediction of manifest functioning was independent of NP and functional test performances. This suggests that some HIV + participants had the basic abilities to function at higher levels, but may have failed to do so because of their affective status. If future research confirms this possibility, there may be substantial benefits for early detection and treatment of depressive symptoms. As part of this process, objective NP and functional tests such as those employed here may help identify patients who have the potential for more independent, productive living.

In addition to possible effects of depression, there may be other reasons why people with CNS disorders fail to perform IADLs as well as their basic abilities would allow. For example, those with adequate abilities to follow a complex medication regimen may fail to do so consistently because of temporary interference from substance use disorders (Hinkin et al., 2004), or even inadequate motivation due to failure to believe that carefully following prescribed methods will actually make a difference. Future research should identify how often failures to accurately follow prescribed medication regimens are due to ability problems versus these other factors, because potentially effective interventions are likely to be different.

In addition to their apparent utility in predicting concurrent everyday functioning, laboratory based functional tests may be useful in measuring clinically significant change in neurobehavioral disorders. For example, such tests could be used as ecologically relevant outcome measures in future clinical trials of medications that may improve the disorders; for HIV related disorders these might include new antiretrovirals or putative neuroprotectants such as memantine or selegiline. However, for these purposes additional information is needed about how the tests perform in a longitudinal context. Future research must establish testretest reliability, provide estimates of practice effects, and develop normative guidelines for determining when a testretest difference is greater than expected in the absence of meaningful change in the patient (Temkin et al., 1999).

In summary, the present findings confirm the importance of assessing NP status in the prediction of everyday functional ability both in the laboratory and in real life, and suggest that HIV-related NP impairments consistent with frontostriatal involvement, in particular, are strongly predictive of functional impairment. In addition, measures of depression and laboratory-based measures of functional ability appear to be key predictors of real-life functioning, such that clinicians' and researchers' appreciation of patients' problems in everyday functioning may indeed be incomplete without such additional information. Future research is needed in order to further investigate the role of depression in functional morbidity of HIV infected persons, evaluate the use of these new functional technologies in other patient populations such as traumatic brain injury, assess their usefulness in measuring ecologically significant change in neurobehavioral status, and extend our understanding of the real-world implications of NP impairments on other important aspects of everyday functioning.

\section{ACKNOWLEDGMENTS}

The HNRC Group includes: Director: Igor Grant, M.D.; CoDirectors: J. Hampton Atkinson, M.D. and J. Allen McCutchan, M.D.; Center Manager: Thomas D. Marcotte, Ph.D.; Naval Hospital San Diego: Mark R. Wallace, M.D. (P.I.); Neuromedical Component: J. Allen McCutchan, M.D. (P.I.), Ronald J. Ellis, M.D., Ph.D., Scott Letendre, M.D., Rachel Schrier, Ph.D.; Neurobehavioral Component: Robert K. Heaton, Ph.D. (P.I.), Mariana Cherner, Ph.D., Julie Rippeth, Ph.D., Joseph R. Sadek, and Steven Woods, Ph.D.; Imaging Component: Terry Jernigan, Ph.D. (P.I.), John Hesselink, M.D.; Neuropathology Component: Eliezer Masliah, M.D. (P.I.); Clinical Trials Component: J. Allen McCutchan, M.D., Ronald J. Ellis, M.D., Ph.D., Scott Letendre, M.D., J. Hampton Atkinson, M.D; Data Management Unit: Daniel R. Masys, M.D. (P.I.), Michelle Frybarger, B.A. (Data Systems Manager); Statistics Unit: Ian Abramson, Ph.D. (P.I.), Reena Deutsch, Ph.D., Tanya Wolfson, M.A.

This study was funded by R01 MH57226-03 (R. Heaton, P.I.) from NIMH, and conducted at the HIV Neurobehavioral Research Center (HNRC), and support for this work was provided by NIH (P50 MH45294; MH57266) and NIDA (P)1 DA 12065).

These data were presented in preliminary form at the Annual Meeting of the International Neuropsychological Society at Chicago, IL in February, 2001.

The authors wish to thank Kate Weinberg for contributing to the development of measures used in this study, and the collection of these data.

\section{REFERENCES}

Albert, S.M., Marder, K.M., Dooneief, G., Bell, K., Sano, M., Todak, G., \& Stern, Y. (1995). Neuropsychologic impairment in early HIV infection: A risk factor for work disability. Archives of Neurology, 52, 525-530.

Albert, S.M., Weber, C.M., Todak, G., Polanco, C., Clouse, R., McElhiney, M., Rabkin, J., \& Marder, K. (1999). An observed performance test of medication management ability in HIV: Relation to neuropsychological status and medication outcomes. AIDS and Behavior, 3, 121-128.

American Academy of Neurology AIDS Task Force. (1991). Nomenclature and research case definitions for neurologic manifestations of human immunodeficiency virus-type 1 (HIV-1) infection. Neurology, 41, 778-785.

Baldessarini, R.J., Finklestein, S., \& Arana, G.W. (1983). The predictive power of diagnostic tests and the effect of prevalence of illness. Archives of General Psychiatry, 40, 569-573.

Beck, A.T. (1987). The Beck Depression Inventory. San Antonio, TX: Psychological Corporation.

Benedict, R.H.B, Mezhir, J.J., Walsh, K., \& Hewitt, R.G. (2000). Impact of human immunodeficiency virus Type-1-associated cognitive dysfunction on activities of daily living and quality of life. Archives of Clinical Neuropsychology, 15, 529-534.

Bornstein, R.A., Nasrallah, H.A., Para, M.F., Whitacre, C.C., Rosenberger, P., Fass, R.J., \& Rice, R. (1992). Neuropsychological performance in asymptomatic HIV infection. Journal of Neuropsychiatry and Clinical Neurosciences, 4, 336-394.

Butters, N., Grant, I., Haxby, J., Judd, L.L., Martin, A., McClelland, J., Pequegnat, W., Schacter, D., \& Stover, E. (1990). Assessment of AIDS-related cognitive changes: Recommendations of the NIMH Workshop on Neuropsychological Assessment 
Approaches. Journal of Clinical and Experimental Neuropsychology, 12, 963-978.

Chelune, G.J., Heaton, R.K., \& Lehman, R.A.W. (1986). Neuropsychological and personality correlates of patients' complaints of disability. In R.E.T. Gerald Goldstein (Ed.), Advances in clinical neuropsychology, Vol. 3 (pp. 95-126). New York: Plenum Press.

Centers for Disease Control. (1992). 1993 revised classification system for HIV infection and expanded surveillance case definition for AIDS among adolescents and adults. Morbidity and Mortality Weekly Report, 41, 1-19.

Diehr, M.C., Heaton, R.K., Miller, W., \& Grant, I. (1998). The Paced Auditory Serial Addition Task (PASAT): Norms for age, education, and ethnicity. Assessment, 5, 375-387.

Gladsjo, J.A., Schuman, C.C., Evans, J.D., Peavy, G.M., Miller, S.W., \& Heaton, R.K. (1999). Norms for letter and category fluency: Demographic corrections for age, education, and ethnicity. Assessment, 6, 147-178.

Grant, I., Atkinson, J.H., Hesselink, J.R., Kennedy, C.J., Richman, D.D., Spector, S.A., \& McCutchan, J.A. (1987). Evidence for early central nervous system involvement in the acquired immunodeficiency syndrome (AIDS) and other human immunodeficiency virus (HIV) infections. Annals of Internal Medicine, 107, 828-836.

Heaton, R.K. (1992). Comprehensive norms for an expanded Halstead-Reitan Battery: A supplement for the WAIS-R. Odessa, FL: Psychological Assessment Resources, Inc.

Heaton, R.K., Grant, I., Anthony, W.Z., \& Lehman, R.A.W. (1981). A comparison of clinical and automated interpretation of the Halstead-Reitan battery. Journal of Clinical Neuropsychology, $3,121-141$.

Heaton, R.K., Grant, I., Butters, N., White, D.A., Kirson, D., Atkinson, J.H., McCutchan, J.A., Taylor, M.J., Kelly, M.D., Ellis, R.J., Wolfson, T., Velin, R., Marcotte, T.D., Hesselink, J.R., Jernigan, T.L., Chandler, J., Wallace, M., Abramson, I., \& the HNRC Group. (1995). The HNRC 500-Neuropsychology of HIV infection at different disease stages. Journal of the International Neuropsychological Society, 1, 231-251.

Heaton, R.K., Grant, I., \& Matthews, C.G. (1991). Comprehensive norms for an Expanded Halstead-Reitan Battery: Demographic corrections, research findings, and clinical applications. Odessa, FL: Psychological Assessment Resources.

Heaton, R.K., Kirson, D., Velin, R.A., Grant, I., \& the HNRC Group. (1994a). The utility of clinical ratings for detecting cognitive change in HIV infection. In I. Grant \& A. Martin (Eds.), Neuropsychology of HIV infection (pp. 188-206). New York: Oxford University Press.

Heaton, R.K., Marcotte, T.D., White, D.A., Ross, D., Meredith, K., Taylor, M.J., Kaplan, R., \& Grant, I. (1996). Nature and vocational significance of neuropsychological impairment associated with HIV infection. Clinical Neuropsychologist, 10, 1-14.

Heaton, R.K. \& Pendleton, M.G. (1981). Use of neuropsychological tests to predict adult patients' everyday functioning. Journal of Consulting and Clinical Psychology, 49, 807-821.

Heaton, R.K., Velin, R.A., McCutchan, J.A., Gulevich, S.J., Atkinson, J.H., Wallace, M.R., Godfrey, H., Kirson, D., Grant, I., \& the HNRC Group. (1994b). Neuropsychological impairment in human immunodeficiency virus-infection: Implications for employment. Psychosomatic Medicine, 56, 8-17.

Hinkin, C.H., Castellon, S.A., Durvasula, R.S., Hardy, D.J., Lam, M.N., Mason, K.I., Thrasher, D., Goetz, M.B., \& Stefaniak, M. (2002). Medication adherence among HIV+ adults: Effects of cognitive dysfunction and regimen complexity. Neurology, 59, 1944-1950.

Hinkin, C.H., Hardy, D.J., Mason, K.I., Castellon, S.A., Durvasula, R.S., Lam, M.N., \& Stefaniak, M. (2004). Medication adherence in HIV-infected adults: Effect of patient age, cognitive status, and substance abuse. AIDS, 18(S1), S19-S25

Jernigan, T.L., Archibald, S., Hesselink, J.R., Atkinson, J.H., Velin, R.A., McCutchan, J.A., Chandler, J., Grant, I., \& the HNRC Group. (1993). Magnetic resonance imaging morphometric analysis of cerebral volume loss in human immunodeficiency virus infection. Archives of Neurology, 50, 250-255.

Lawton, M.P. \& Brody, E.M. (1969). Assessment of older people: Self-maintaining and instrumental activities of daily living. Gerontologist, 9, 179-186.

Lowenstein, D.A., Duara, R., Rubert, M.P., \& Arguelles, T. (1995). Neuropsychological test performance and prediction of functional capacities among Spanish-speakers and English-speaking patients with dementia. Archives of Clinical Neuropsychology, $10,75-88$.

Lowenstein, D.A. \& Bates, B.C. (1992). Manual for administration and scoring the Direct Assessment of Functional Status scale for older adults (DAFS). Miami Beach, FL: Mount Sinai Medical Center.

Mapou, R.L., Law, W.A., Martin, A., Kampen, D., Salazar, A.M., \& Rundell, J.R. (1993). Neuropsychological performance, mood, and complaints of cognitive and motor difficulties in individuals infected with the human immunodeficiency virus. Journal of Neuropsychiatry and Clinical Neurosciences, 5, 86-93.

Marcotte, T.D., Heaton, R.K., Wolfson, T., Taylor, M.J., Alhassoon, O., Arfaa, K., Grant, I., \& the HNRC Group. (1999). The impact of HIV-related neuropsychological dysfunction on driving behavior. Journal of the International Neuropsychological Society, 7, 579-592.

Salthouse, T.A. (1990). Influence of experience on age differences in cognitive functioning. Human Factors, 32, 551-569.

Salthouse, T.A. (1994). Age-related differences in basic cognitive processes: Implications for work. Experimental Aging Research, 20, 249-255.

Schiffito, G., Kieburtz, K., McDermott, M.P., McArthur, J., Marder, K., Sacktor, N., Palumbo, D., Selnes, O., Stern, Y., Epstein, L., \& Albert, S. (2001). Clinical trials in HIV-associated cognitive impairment: Cognitive and functional outcomes. Neurology, 56, 415-418.

Stern, Y., Marder, K., Bell, K., Chen, J., Dooneief, G., Goldstein, S., Mindry, D., Richards, M., Sano, M., Williams, J., Gorman, J., Ehrhardt, A., \& Mayeux, R. (1991). Multidisciplinary assessment of homosexual men with and without human immunodeficiency virus infection. III. Neurologic and neuropsychological findings. Archives of Neurology, 48, 131-138.

Stout, J.C., Ellis, R.J., Jernigan, T.L., Archibald, S.L., Abramson, I., Wolfson, T., McCutchan, J.A., Wallace, M.R., Atkinson, J.H., Grant, I., \& the HNRC Group. (1998). Progressive cerebral volume loss in human immunodeficiency virus infection: A longitudinal volumetric magnetic resonance imaging study. Archives of Neurology, 55, 161-168.

Temkin, N.R., Heaton, R.K., Grant, I., \& Dikmen, S.S. (1999). Detecting significant change in neuropsychological test performance: A comparison of four models. Journal of the International Neuropsychological Society, 5, 357-369.

U.S. Department of Labor. (1991a). Dictionary of occupational titles (4th ed.). Washington, DC: U.S. Government Printing Office. 
U.S. Department of Labor. (1991b). Revised handbook for analyzing jobs. Washington, DC: U.S. Government Printing Office.

Valpar International Corporation. (1986). Microcomputer Evaluation and Screening Assessment (MESA) Short Form 2. Tucson, AZ: Author.

Valpar International Corporation. (1992). Computerized Assessment (COMPASS). Tucson, AZ: Author.
Woods, S.P., Weinborn, M., \& Lovejoy, D.W. (2003). Are classification accuracy statistics underused in neuropsychological research? Journal of Clinical and Experimental Neuropsychology, 25, 431-439.

Zweig, M.H. \& Campbell, G. (1993). Receiver-operating characteristic (ROC) plots: A fundamental evaluation tool in clinical medicine. Clinical Chemistry, 39, 561-577.

\section{Appendix}

${ }^{\circledR}$ LOPEROL CAPSULES

\section{COMPOSITION:}

$2 \mathrm{mg}$ loperamide hydrochloride per capsule.

\section{INDICATIONS:}

Symptomatic treatment of acute diarrhea.

\section{CONTRA-INDICATIONS:}

- Known sensitivity to loperamide.

- Safety in pregnancy and lactation has not been established.

- LOPEROL must not be used when inhibition of peristalsis is to be avoided, in particular where constipation is present or in patients with inflammatory bowel disease. Discontinue use immediately if constipation or abdominal distension develop.

\section{WARNINGS:}

- Patients with inflammatory bowel disease receiving loperamide should be carefully observed for signs of toxic megacolon.

- Keep out of reach of children.

- If no improvement in acute diarrhea has been observed after 48 hours, LOPEROL should be discontinued.

\section{DOSAGE AND DIRECTIONS FOR USE:}

This product is not intended for use in children under the age of 9 years.

\section{Adults:}

Two capsules initially, followed by one capsule after each loose stool. The usual dosage is 3 to 4 capsules a day. The maximum daily dose should not exceed 8 capsules.

Children 9 to 12 years:

One capsule four times daily until diarrhea is controlled.

\section{SIDE-EFFECTS AND SPECIAL PRECAUTIONS:}

Abdominal cramps and bloating as well as skin reactions have been reported. Dry mouth, dizziness and fatigue may occur.

\section{KNOWN SYMPTOMS OF OVERDOSAGE AND PARTICULARS OF ITS TREATMENT:}

Overdosage may lead to constipation and depression of the central nervous system. Children may be more sensitive to central nervous system depressant effects of loperamide than adults. Convulsions have been reported in children under the age of 2 years.

\section{STORAGE INSTRUCTIONS:}

Keep well closed and store in a dry place below $25^{\circ} \mathrm{C}$. Keep out of reach of children.

${ }^{\circledR}$ Registered Trademark

Information presented by Malahyde Information Systems (C) Copyright 1996, 1997, 1998 